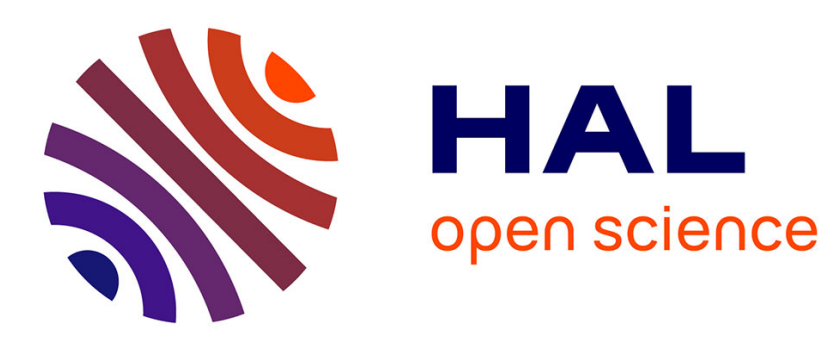

\title{
What Is Said, Linguistic Meaning and Directly Referential Expressions
}

Isidora Stojanovic

\section{To cite this version:}

Isidora Stojanovic. What Is Said, Linguistic Meaning and Directly Referential Expressions. Philosophy Compass, 2006, 1, pp.1-25. 10.1111/j.1747-9991.2006.00029.x . ijn_00000624v2

\section{HAL Id: ijn_00000624 \\ https://hal.science/ijn_00000624v2}

Submitted on 8 Mar 2006

HAL is a multi-disciplinary open access archive for the deposit and dissemination of scientific research documents, whether they are published or not. The documents may come from teaching and research institutions in France or abroad, or from public or private research centers.
L'archive ouverte pluridisciplinaire HAL, est destinée au dépôt et à la diffusion de documents scientifiques de niveau recherche, publiés ou non, émanant des établissements d'enseignement et de recherche français ou étrangers, des laboratoires publics ou privés. 


\title{
What Is Said, Linguistic Meaning, and Directly Referential Expressions
}

\author{
Isidora Stojanovic \\ CNRS/Institut Jean-Nicod, 1bis av Lowendal, 75007 Paris, France, and \\ Stanford University, Dept. of Philosophy, Stanford, CA 94305-2155, USA \\ isidora@stanford.edu
}

\begin{abstract}
Philosophers of language distinguish among the lexical or linguistic meaning of the sentence uttered, what is said by an utterance of the sentence, and speaker's meaning, or what is conveyed by the speaker to her audience. In most views, what is said is the semantic or truth-conditional content of the utterance, and is irreducible either to the linguistic meaning or to the speaker's meaning. I will show that those views account badly for people's intuitions on what is said. I will also show that no distinguished level of what is said is required, and that the notion of linguistic meaning is the best placed to play the role of what is said. This relies on two points. First, our intuitions on what is said cannot be detached from the ways in which we talk about what is said, and from the semantics of speech reports and indirect discourse in general. Second, beside what is said, there is an equally important notion of what what-is-said is said about, or that about which the speaker is talking. Here are, then, the three ingredients needed for the theory of what is said: linguistic meaning, what is talked about, and the semantics of reported speech.
\end{abstract}

\section{The Received Wisdom about What Is Said, What Is Conveyed, and Linguistic Meaning}

In everyday life, we say things, and the things we say may change our lives, affect our relationships and careers, and one may even go to jail because of what one has said. There is no doubt that people have a certain intuitive notion of what is said, and attempts have been made to account for it. In philosophy of language, what is said (by someone who utters a meaningful string of sounds) is normally identified with the truth-conditional content of the utterance, that is, some set of conditions such that the utterance is true if and only if those conditions obtain. Such truth conditions are most often seen as conditions on what the world must be like for the utterance to be true. Suppose that on 15 July 2005 at noon I am in Prof. Jones' office, and I say:

(1) It's cold in here.

To determine the truth value of my utterance, one needs to determine whether it was cold in Jones' office at noon on 15 July 2005: if it was, then (1) is true, and if it was not, then (1) is false. This is why most views take the truth-conditional content of (1) 
to correspond to the set of all those worlds in which at $12 \mathrm{pm}, 15 / 07 / 05$, it is cold in Jones' office.

We know from the speech-act theory that making utterances is a way of doing things. Consider (1) again. My interlocutor may reason that if I told her (1), that was not to inform her that it was cold in her office, which she already knew. Hence I must have intended to inform her of something else, like the following:

(2) I want you to close the windows.

My utterance of (1) clearly does not say the same thing as (2) (if I were to utter it), but in the context at stake, (1) conveys what (2) says. The distinction between what is said and what is conveyed, or conversational implicature, has been discussed a lot since Grice, and I will have little to say about it here (cf. Grice (89), Levinson (00), Carston (02)).

Our lexical knowledge of what the words uttered mean need not always determine what is said by the utterance. But the move from lexical meaning to what is said is supposed to be fairly direct, requiring only knowledge of some basic parameters of the context of utterance: who is speaking, to whom, where and when, and to what they are referring. Thus in (1), the linguistic meaning of the words uttered tells you that (1) is true if it is cold in there, that is, where the utterance is made. To determine the truth value of (1), one needs to determine first where the utterance is made, and once this is seen to be Jones' office, we get that (1) is true if and only if it is cold in Jones' office.

What is said is thus normally seen as something that can be obtained in a more or less straightforward way from the linguistic meaning of the words uttered, the syntax of the sentence, and the basic contextual parameters. By contrast, what is conveyed heavily depends on the context and requires you to reason about the beliefs and intentions of your interlocutors, considerable general knowledge, and inference to the best explanation. For instance, my utterance of (1) may also convey the opposite of what it conveyed in our previous scenario. Suppose that 15 July is a very warm day, but Jones' office is so air-conditioned that it is freezing in there. Then by uttering (1) I could convey the following:

(3) I want you to open the windows.

The ways in which what is said and what is conveyed depend on the context has led some some philosophers, such as Kent Bach, to distinguish between narrow and broad context. Caricaturing somewhat, the standard view may thus be captured with these two equations: ${ }^{1}$

\footnotetext{
${ }^{1}$ The schema is compatible with two views on the role of syntax in the determination of what is said. One view holds that it is possible to assign a linguistic meaning to the entire (nonambiguous) sentence, so that the only parameters of the narrow context are, roughly, the speaker and the spatio-temporal location of the utterance. The other view holds that linguistic meanings can only be assigned to words, but not to larger syntactic compounds. In that case, syntactic structure may be seen as provided by the narrow context (see King and Stanley (02) for discussion).
} 
linguistic meaning + narrow context $=$ what is said

what is said + broad context $=$ what is conveyed

In what follows, I will try to show that the notion of what is said supposed to fit the two equations is at best a theoretical artifact, with two major shortcomings: it fails to account for a large portion of our intuitions on what is said, and it does not extend into a fine semantic account of reported speech and locutions such as 'what he/she said'. Furthermore, the cases that I will appeal to actually appear to support this much simpler view:

linguistic meaning $=$ what is said

linguistic meaning + context $=$ what is conveyed

Clearly, if such a theory can be worked out, it will be preferable on the grounds of parsimony and elegance, given that it does not require any distinguished level of what is said.

\section{Linguistic Meaning vs. What Is Said}

At a first glance, one might plausibly suppose that the linguistic meaning associated with a sentence is the most obvious candidate to play the role of what is said by an utterance of that sentence. I want to argue that this is indeed a very plausible view. However, as already noted, this view is widely rejected nowadays. It will help, then, to start with those cases that have motivated its rejection. For simplicity, in this paper I will only consider a small fragment of English, including pronouns, ordinary proper names, some spatio-temporal adverbs, and definite descriptions, without considering the problems raised specifically by these.

\subsection{Different Meanings, Same Things Said}

The first motivation for a distinguished level of what is said comes from utterances whose speakers intuitively say the same thing, even though the sentences that they use do not have the same linguistic meaning. Suppose that I say:

(4) I have been injured.

By uttering (4), I may inform you that I have been injured. Now, suppose that you want to inform someone else, say Sonia, of this. You cannot use the same sentence that I used, because then you would inform her that you, not I, have been injured. I can refer to myself using the first person pronoun, but you need to find another way of referring to me. For instance, you might say:

(5) Isidora has been injured. 
Or, if your conversation with Sonia already happens to be about me, you might just say:

(6) She has been injured.

It is widely agreed that the sentences in (4), (5) and (6) have different meanings, because different linguistic conventions are associated with pronouns 'I' and 'she' and proper names. The $1^{\text {st }}$ person pronoun is used for the speaker, the $3^{\text {rd }}$ person pronoun, for some salient female, and the name, for a bearer of that name. Still, it is almost as widely held that what you say in (5) or (6) and what I say in (4) is one and the same thing - something like the proposition true in those and only those worlds in which I, Isidora, have been injured before the time of my utterance. This intuition goes back at least to Frege, who wrote: "It is not necessary that the person who feels cold should himself give utterance to the thought that he feels cold. Another person can do this by using a name to designate the one who feels cold" $\left(1897\right.$, p. 236). ${ }^{2}$

\subsection{Same Meanings, Different Things Said}

The second motivation for the standard view is the idea that you can use one and the same non-ambiguous sentence to express different things, provided that you use it in different contexts. This insight, too, goes back to Frege: "The sentence 'I am cold' expresses a different thought in the mouth of one person from what it expresses in the mouth of another" (ibid). Frege's insight has been taken up by David Kaplan: "What is said in using a given indexical in different contexts may be different. Thus if I say, today, "I was insulted yesterday," and you utter the same words tomorrow, what is said is different [...] There are possible circumstances in which what I said would be true but what you said would be false. Thus we say different things" (77, p. 500).

Kaplan argued that there are two levels of meaning. Suppose that David Kaplan says "I was insulted yesterday" on 15 July 2005. Then there is a level of meaning independent of the context of his utterance; that is, a level of meaning that captures speakers' lexical knowledge and that tells you that this sentence may be used to say of the speaker and the day before the utterance that he or she was insulted then. Such descriptive, lexically encoded conditions that help you determine the reference, such as being the speaker for the indexical 'I', or a salient female for the pronoun 'she', or being called 'David' for the name 'David', correspond to what Kaplan calls character. ${ }^{3}$

${ }^{2}$ A thought in Frege's terminology can, here at least, be thought of as what is said, as the phrase is used in the more recent literature. To be sure, there is controversy as to what was Frege's theory of indexicals (assuming that he had any), but this is irrelevant to the present discussion.

${ }^{3}$ For proper names, there is considerably less agreement that they have any kind of linguistic meaning. Kaplan himself, for instance, holds that proper names don't have characters in any non-trivial sense. (In his formal system, the character of a proper name is a constant function from contexts to individuals, whose value varies neither with the context nor with the world of evaluation.) Here, however, I will be assuming the so-called metalinguistic view, which takes the linguistic meaning of a name to be the condition of being called by or being a bearer of 
Then, there is a level of meaning that a sentence has only relative to some context of utterance, and that we obtain by factoring contextual information into linguistic meaning. This second level of meaning, which Kaplan calls 'content', would, in the previous example, be the proposition that David Kaplan was insulted on 14 July 2005. The interaction between the two levels, and between them and the level of truth and reference, may be thought of as follows. The character of an expression, given some context of utterance, gives you the expression's content; and the content, given some circumstance of evaluation, gives you the expression's reference. In the case of a sentence, its character, given a context, gives you a proposition, and the latter, given a world of evaluation, gives you a truth value.

Since Kaplan, most philosophers virtually take it for granted that once you have directly referential expressions in the language, such as demonstratives, indexicals and names, linguistic meaning differs from what is said in two respects: [1] there is something in what is said that is not in the linguistic meaning, namely, the reference of the directly referential expression; [2] there is something in the linguistic meaning that is not in what is said, namely, the descriptive conditions lexically recorded in the character. As François Recanati puts it, "the property of being the addressee is not a constituent of the proposition expressed [by utterances containing 'you']: it is used only to help the hearer identify the reference, which is a constituent of the proposition expressed." (93, p. 39)

\section{The Landscape Today}

It is interesting that almost everyone today accepts this twofold difference between linguistic meaning and what is said. Almost everyone holds that the referent of any directly referential expression is a constituent of what is said without being part of the linguistic meaning, while the descriptions associated the expression are part of the linguistic meaning without reaching into what is said. This view of directly referential expressions, their linguistic meaning and their contribution to what is said appears to be so entrenched in the contemporary philosophy of language that it is sometimes the only thing agreed upon by authors whose views are otherwise radically different. It is beyond the scope of this paper to try to depict the theoretical landscape in any thorough or systematic way. Let us simply take a few glances at this landscape, so as to be aware of the variety of approaches to what is said defended today.

\subsection{The Main Camp (Literalism)}

The view that has emerged from Saul Kripke's Naming and Necessity and David Kaplan's Demonstratives is the most widely adopted view, whose adherents include people like Marga Reimer, Nathan Salmon, Scott Soames, Robert Stalnaker, Jason

that name. For argument and discussion, see Recanati (93); for a defense of the metalinguistic view from the standpoint of semantics, see Geurts (97). 
Stanley, Ken Taylor, and many others. Although there are many subtle differences and points of disagreement among these authors, all of them draw a sharp distinction between linguistic meaning and what is said. Furthermore, they take what is said to be propositions, traditionally conceived; which is to say, eternal propositions, whose truth values depend on what the world is like, but do not vary with other things, such as times or places or individuals. ${ }^{4}$

Literalists hold that in the case of "pure" indexicals, such as the $1^{\text {st }}$ and the $2^{\text {nd }}$ person pronouns and adverbs 'here', 'now', 'today' and the like, the linguistic meaning itself is determinate enough to fix the reference, and hence determine what is said by the utterance. For example, the linguistic meaning of 'I' tells you that its referent is the speaker, and since there is always a unique speaker in any given context, the move from the linguistic meaning to what is said is pretty much automatic. But they also accept that in certain cases, the linguistic meaning is too poor to determine what is said. Demonstrative pronouns are the case at point: the linguistic meaning of 'he', which amounts to something like 'salient male individual', only constraints the referent of 'he', but in order to determine the actual referent, who will then go into what is said, one must take into account certain pragmatic facts about the utterance, such as which individual was jointly attended to by the speaker and her audience in the context of utterance. But the appeal to pragmatics is triggered here by something from the sentence itself, namely the $3^{\text {rd }}$ person pronoun. The trademark of literalism is precisely that all the pragmatics involved in the determination of what is said must be constrained by semantics.

Most literalists acknowledge that there need not always be an overt, phonetically articulated element in the sentence to trigger the pragmatic resolution of an element that will go into what is said. Consider:

(7) Every bottle is empty.

If Sonia utters (7) at a party, she likely means to be saying that every bottle at that party is empty. In most views, the intended domain of quantification is taken to be part of what is said. For instance, what is said by (7) would be the proposition true in those and only those worlds in which every bottle at the party is empty (at that world, at the time of utterance). In the context described, we take (7) to be false if some bottle at the party is not empty, but we do not take (7) to be false just because there is some bottle somewhere in the world that is not empty. If people's intuitions on truth values are to be taken seriously, as contemporary semantics does, and if what is said is conceived of as being a proposition, which varies in truth value along the possible world dimension, but not along other dimensions such as times, locations or domains

\footnotetext{
${ }^{4}$ The main camp is divided between those who conceive of propositions as structured entities and those who model propositions by sets of possible worlds. It should be noted, too, that in his formal system, Kaplan models contents as functions that map pairs consisting of a possible world and a time to truth values, which is to say that such contents can and normally do take different truth values at different times. However the informal understanding of what is said that has subsequently emerged from Kaplan's work remains tied to the traditional notion of proposition, that is, something that, if true, is true once and for all, and if false, is similarly false once and for all.
} 
of quantification, then it is easy to understand why the domain of quantification, or other parameters that similarly affect the truth value, have been seen as elements of what is said.

Indexicalism, a special variant of literalism, holds that for any element that reaches into what is said, there must be some element in the syntax of the sentence uttered whose semantic interpretation will trigger a pragmatic process, such as those involved in interpreting demonstratives, that will help determine what is said. As Stanley writes: "All effects of extra-linguistic context are traceable to elements in the actual syntactic structure of the sentence uttered" $(00$, p. 391). Be that as it may, what literalists insist on is that the pragmatic processes that bridge the gap between linguistic meaning and what is said should always be semantically driven.

\subsection{Contextualism}

It is on this very last point that contextualism departs from literalism. ${ }^{5}$ Contextualists hold that the linguistic meaning, to the extent that the notion makes sense at all, only loosely constrains what is said. Various pragmatic processes may affect what is said, without being triggered by any syntactic or semantic property of any element in the sentence uttered. Consider for example:

(8) Jones took out her key and opened the door.

A contextualist wants to say that part of what is said in (8), in the situation imagined, is that Jones took the key out of her purse and that she opened the door with that key. But there does not seem to be any element in the sentence uttered that invites the interpreter to identify Jones' purse as that out of which she took her key, and there is nothing that stands for how she opened the door (viz. with the key). Rather, it is the conversational context itself that makes it part of what is said in (8) that she took the key out of her purse and used it to open the door.

It is worth noting that on the issue of what it is that directly referential expressions such as names or pronouns contribute to what is said, contextualists are pretty much in agreement with literalists in that they hold that it is the expression's referent, and nothing but the referent, that reaches into what is said.

\footnotetext{
${ }^{5}$ A remark about the labels is in order. Some authors that I have included in the main camp are already qualified, say, by Cappelen and Lepore (05), as moderate contextualists. Recanati (04) proposes a somewhat different taxonomy. He reserves the label 'contextualism' for those views that allow optional pragmatic processes, not triggered by anything in the sentence uttered, to enter into the determination of what is said. Recanati's further distinction between moderate and radical contextualism turns upon the question of whether the notion of the minimal proposition expressed, determined by the syntactic and semantic properties of the sentence uttered, makes any sense. (On Recanati's understanding of contextualism, the two views hold that the minimal proposition, if there is such a thing, does not play a role in determining what is said.) I adopt Recanati's taxonomy, but I will not bother to draw this further distinction between moderate and radical contextualism.
} 
It is sometimes believed that contextualism tries to get rid of linguistic meanings all together. But without being clear on what we understand by linguistic meanings, this claim is hard to evaluate. Contextualists certainly want to say that the sentence itself does not express anything merely in virtue of its lexical meaning; that is, anything that can be evaluated for truth or falsity relative to a possible world. ${ }^{6}$ However, contextualists do not deny that words have meanings, albeit very flexible and often underdeterminate, tied to the notion of speakers' lexical knowledge. They also talk of the semantic potential even of complex expressions, and what has been understood here by the linguistic meaning of a sentence need not be anything more specific or proposition-like than such semantic potentials.

\subsection{Variants and Alternatives}

Certain accounts can hardly be assimilated to either camp. Let us briefly look at three such: semantic minimalism, Perry's reflexive-referential theory, and Bach's theory of implicitures.

\subsection{Minimalism}

Semantic minimalism, a view defended, for instance, by E. Borg, H. Cappelen, E. Lepore, or J. Saul, is a variant of literalism that tries to minimize, if not outright abolish, the role of pragmatics in the determination of semantic or truth-conditional content and of what is said. For example, in cases such as (7), minimalists typically deny that the domain of quantification relevant to the truth value of a given utterance is determined by the context. They would say instead that (7) is true if and only if every bottle is empty, so that some non-empty bottle somewhere in the world would be enough to falsify (7), regardless of what the party situation is like.

Strangely enough, though, when it comes to directly referential expressions, these "minimalists" do hold that the semantic content is richer than the linguistic meaning, given that it includes the contextually specified referents of such expressions, but not their characters. On this score, there is very little divergence between contextualism and minimalism, views believed to be radically opposed.

\footnotetext{
${ }^{6}$ Of course, it we take the relevant parameters of evaluation to be contexts, or situations, rather than possible worlds, then it is no longer clear that the contextualist would want to deny that the sentence qua sentence expresses anything; only, that thing is very different from what people think are the things that get expressed, which is, propositions. It is something that gives you a proposition and is susceptible of having a truth value only relative to some context of utterance, as broad as you like. For a discussion of the contextualist challenge to traditional semantics see, for instance, Predelli (05) and Predelli (forthcoming).

${ }^{7}$ Cappelen and Lepore actually have a rather elaborate view on what is said. While they hold that the semantic content associated with an utterance is a proposition determined by the linguistic meaning of the sentence and only the most basic pragmatic factors, such as who is speaking, where and when, they abstain from identifying semantic contents with what is said. In their view, there are indefinitely many things "said" by any given utterance, because there can be indefinitely many possible reports of what has been said. Cf. Cappelen \& Lepore (97).
} 


\subsection{Perry's Reflexive-Referential Theory}

John Perry has argued that it is misleading to talk of the proposition expressed by an utterance or of the truth-conditional content. For, there is a wide array of propositions that may be associated with any given utterance, all of which provide, in one way or another, a necessary and sufficient condition for the utterance to be true. Suppose again that on 15 July 2005, David Kaplan says "I was insulted yesterday." The truthconditional content that the traditional view associates with this utterance is the proposition that Kaplan was insulted on 14 July 2005, while in Perry's view, that is simply one among the contents associated with the utterance. There is also what he calls the reflexive content, which captures the truth conditions of the utterance known by any competent speakers, regardless of their knowledge of the context of utterance. Thus, in virtue of what the words uttered by Kaplan mean in English, we know that his utterance is true if and only if the speaker of that utterance was insulted on the day before the utterance. Linguistic meaning is thus captured in terms of reflexive content. What is novel in Perry's theory is that the move from reflexive content (or linguistic meaning) to the truth conditions as traditionally thought of may consist in several steps, each of which results in a content that specifies a certain truth condition for the utterance. For example, if you start from the reflexive content of Kaplan's utterance above, and you add the fact that it is David Kaplan who made it, you get that the utterance is true if and only if Kaplan was insulted on the day before the utterance. Similarly, if you start from the reflexive content and add the fact that the utterance was made on 15 July 2005 , you get that the utterance is true if and only if the speaker, whoever he or she may be, was insulted on 14 July 2005. Finally, if you increment the reflexive content with the two facts together, you get that the utterance is true iff David Kaplan was insulted on 14 July 2005, which is the content that the main camp view would associate with the utterance.

Having stressed that "the binary distinction (...) is too simple," Perry writes: "an utterance has as wide a variety of contents as we may find useful to isolate, for particular purposes of description and explanation. We can say that in at least the vast majority of cases, the common sense concept of "what is said" corresponds to content $_{\mathrm{C}}$ [ie, the usual propositional content]. This is a good reason for an account of content to recognize this concept, but not a good reason to expect it to be the only or even the most theoretically fruitful kind of content" $(97$, p. 17)

Thus even though Perry's view alines with the traditional view insofar as the notion of what is said goes, it is more flexible and better equipped to deal with certain problematic cases. ${ }^{8}$

\subsection{Bach's Theory of Implicitures}

Let us close this overview of the theoretical landscape with the notion of impliciture, due to Kent Bach. The motivation for this notion is twofold. Suppose that Sonia says "Olaf is ready." What is, one might ask, the truth-conditional content of Sonia's

\footnotetext{
${ }^{8}$ In my (03), I show how Perry's theory can handle certain cases that Kaplan's theory cannot, but I also show that Perry's account, as it stands, is too flexible, and needs to be amended in order not to predict that two given utterances express the same content when, intuitively, they do not.
} 
utterance? It seems difficult to hold that her utterance is true if and only if Olaf is ready, ${ }^{9}$ because it is not clear what the world should be like for Olaf to be ready simpliciter. Rather, to be ready is to be ready for something, and that for which Olaf is said to be ready is something that the hearer must figure out from the context of utterance. Now, in Bach's view, what is said by Sonia is indeed nothing more than that Olaf is ready, but he also points out that this is not a full-fledged proposition. It is what Bach calls a propositional radical, which can be fleshed out into a proposition by specifying that for which Olaf is said to be ready. For instance, what Sonia might want to communicate is that Olaf is ready to leave home to go to work. This process Bach calls completion, and what you obtain is the proposition that Olaf is ready to leave home to go to work, which is the impliciture associated with Sonia's utterance. It is the impliciture that gets communicated, even though what is said is only the propositional radical.

The other motivation for implicitures comes from those cases in which there is a mismatch between what the speaker literally says and what it is reasonable to suppose that she means to be saying or communicating. Reconsider (7), that is, "Every bottle is empty," uttered by Sonia at a certain party. Here, what is said is fully propositional. There are clear truth conditions for her utterance, namely, that it is true if and only if every bottle (simpliciter) is empty. However, as noted above, it is more reasonable to suppose that Sonia means to be saying only of the bottles at the party that they are empty. This process Bach calls expansion, and it, too, gives rise to implicitures, such as the proposition that every bottle at the party is empty: "impliciture can be a matter of either filling in or fleshing out what is said. Completion is the filling in of a propositional radical, and expansion is the fleshing out of the minimal proposition expressible by an utterance" (94, p. 144).

Finally, what distinguishes implicitures for the usual Gricean implicatures is that the former are "closely related to what is said" (ibid., p. 126). Impliciture is what gets communicated and is already implicit in what is said. Implicature, on the other hand, is something that the hearer must infer, using general knowledge and inference to the best explanation, from what the speaker said or communicated and from her saying or communicating it.

\section{Problems}

I will now go through a series of problems for the standard theories of what is said, only some of which have been raised or discussed in the literature. ${ }^{10}$

\footnotetext{
${ }^{9}$ Note, though, that this is precisely what minimalists are eager to maintain.

${ }^{10}$ There is a well-known kind of problematic cases for the referential theories, the so-called Hesperus/Phosphorus cases. As applied to the notion of what is said, the problem is roughly this. Suppose that Olaf says "Hesperus is bright in the morning." Since Hesperus just turns out to be Phosphorus, the proposition expressed by Olaf's utterance is the same as it would be if he had said instead "Phosphorus is bright in the morning." However, it is unclear that intuitively he would be saying the same thing, and more importantly, we can think of contexts in which
} 


\subsection{Time-Neutral and Location-Neutral What Is Said}

It is widely held that in simple sentences, the present tense works like a referential expression (cf. Partee (73)). It picks out a specific time, normally the time of the utterance, and brings it into the semantic content and thereby into what is said by the utterance. The problem is that if what is said is thus tied to a specific time, there will be many cases in which people have the intuition that the same thing has been said, and will easily report what has been said as being the same, even though the contents of the reported utterances do not coincide on the time picked out by the present tense. To see the point, it is enough to reconsider one of our previous examples:

(9) She has been injured. (Sonia talking of Jones, on Monday)

(10) Jones has been injured. (Miles talking to Dorsky, on Tuesday).

(11) That's what Sonia said, too. (Dorsky's reply)

The report in (11) is intuitively true. ${ }^{11}$ We easily take Sonia and Miles to have said the same thing, namely, that Jones has been injured, even though their utterances are made at different times and therefore have different contents, namely, that Jones was injured prior to $t_{1}$, the time of Sonia's utterance, vs. that she was injured prior to $t_{2}$, the time of Miles' utterance.

Note that not only the contents, but the linguistic meanings of the sentences uttered are different, too. The meaning of the proper name tells you to pick out a bearer of that name, while the $3^{\text {rd }}$ person pronoun 'she' tells you to pick out a salient female. The intuition that Jones and Miles say the same thing cannot, then, be explained by their having uttered the same sentence, since they have not.

Some might think that the reason why we can so easily report Sonia and Miles as having said the same thing is this. It is a fact that if some event $e$ has happened prior to time $\mathrm{t}_{1}$, and if $\mathrm{t}_{1}$ is before $\mathrm{t}_{2}$, then event $e$ has happened prior to time $\mathrm{t}_{2}$. It follows that the truth of Jones' utterance entails the truth of Miles' utterance. In section 4.3., we will see more cases that suggest that when the truth of $u_{1}$ entails the truth of $u_{2}$, we tend to report what is said by $\mathrm{u}_{2}$ as having been already said by $\mathrm{u}_{1}$.

However, there are many cases in which intuitively, we say the same thing, even though the temporally specified contents of our utterances are neither the same, nor does one entail the other. Consider Jones in London, on 15 July 2005, saying:

the truth value of reports of what Olaf has said are sensitive to the choice of the name that he has used. This problem of substitution failures of co-referential names in opaque contexts has given rise to a huge literature, which is why I abstain from tackling it here. See eg Salmon (86) or Soames (02) for a defense of the referential treatment that explains away the intuitions on what is said and on the truth value of speech/belief reports. See eg Crimmins and Perry (89) or Recanati (03) for alternative referential accounts that respect the intuitions, while still treating proper names as directly referential expressions.

${ }^{11}$ A note about the methodology adopted in this paper. The intuitions have been gathered from three native English speakers, and three native French speakers for analogous cases in French. Of course, we can only speculate that if tested more broadly and in a better controlled way, the intuitive judgments of truth and falsity of these reports will still be the same. 
(12) It is cold and windy.

Suppose now that three days later, Miles says in San Francisco:

(13) It is cold and windy.

There is clearly a sense in which Jones and Miles are saying the same thing. For, they are both saying that it is cold and windy. While saying the same thing, namely, that it is cold and windy, Jones is talking of London on the $15^{\text {th }}$ of July, and Miles is talking of San Francisco on the $18^{\text {th }}$ of July, which is why their utterances need not have the same truth value. Still, this difference in truth value does not mean that what is said is different; or at least, there is no obvious reason why it should. Note, though, that when we say the same thing in the sense in which (12) and (13) say the same thing, but are also talking of the same thing, our utterances will have the same truth value.

The standard theories assign different contents to (12) and (13). (12) is taken to express the proposition that it is cold and windy in London on 15 July 2005, and (13), the proposition that it is cold and windy in San Francisco on 20 July 2005. What these theories need here are time-neutral and location-neutral contents, ie contents that are functions not only of possible worlds, but also of times and places. ${ }^{12}$ But time-neutral contents have not always been welcomed (Evans (79)), so some might try to avoid introducing them. To account for the intuition that Jones and Miles are saying the same thing, namely that it is cold and windy, defenders of propositional contents might point out that Jones and Miles are using the same sentence, albeit to express different propositions. And perhaps we report what is said as being the same simply because the sentences uttered are the same.

Though this account might work fine for (12)-(13), it fails to generalize. Suppose that on Wednesday 20 July, Jones, Miles and Dorsky are together in San Francisco, and it is incredibly cold and windy. The next day in Stanford, Jones says to Miles:

(14) It is cold and windy, though less than yesterday in the city. ${ }^{13}$

Next, suppose that on Saturday, 23 July, in London, Dorsky says to Miles:

(15) It is cold and windy, though less than Wednesday in San Francisco.

Miles might then reply to Dorsky, based on the conversation that he had had with Jones:

(16) Jones said that, too.

\footnotetext{
${ }^{12}$ As previously noted, Kaplan's formal system does employ contents that are functions of times. However, the intuitive notion of what is said, for Kaplan as well as for his followers, is time-specific.

${ }^{13}$ A remark on the geographical setting of the example: in Stanford, and generally in the Bay Area, 'the city' is normally used to refer to San Francisco.
} 
The intuitions here are that Miles' reply is just fine, he is not saying anything false. There is certainly a sense in which Jones and Dorsky are saying the same thing, for they are both saying that it is cold and windy, but less than in San Francisco on 20 July 2005. And this might account for the intuition that (16) is true, when properly disambiguated.

Once we accept that there is a sense in which what is said by (14) is the same as what is said by (15), and once we start looking for a semantics of speech reports on which Miles' report in (16) comes out true (on one of its readings), we can no longer stick with the traditional view. For, the propositions expressed by (14) and (15) are different, the one being that Stanford on July 21 is less cold and windy than San Francisco on July 20, the other being that London on July 23 is less cold and windy than San Francisco on July 20. However, in contrast with the case of (12) and (13), the sentences used by Jones and Dorsky have different linguistic meanings. In (14), 'yesterday in the city' bids you to look for a salient city and a day before the day of an utterance of 'yesterday'. In (15), 'Wednesday in San Francisco' bids you to look for a salient Wednesday and a place that bears the name 'San Francisco'. If, for instance, Dorsky were to use the same sentence as Jones, her utterance would be true if on July 23, in London, it was less cold and windy than on July 22, presumably again in London.

In sum, the standard account of what is said faces a challenge when presented with utterances that do not concern the same spatio-temporal locations, nor are utterances of the same sentence, and yet, people have no problem hearing them and reporting them as saying the same thing.

\subsection{Same Meanings, Same Things Said}

Let us go back to the $1^{\text {st }}$ person pronoun 'I'. Suppose that Jones says:

(17) I have been injured.

Next, suppose that, possibly at a different time, Dorsky says:

(18) I have been injured.

Despite Frege's intuition that Jones and Dorsky will express different thoughts, and despite Kaplan's echoing claim that different people using the $1^{\text {st }}$ person pronoun say different things, people have equally strong intuitions that in some important sense, what Jones says in (17) is the same as what Dorsky says in (18). They each say that they have been injured. ${ }^{14}$ Similarly, consider Miles who, having heard Jones in (17), now replies to Dorsky in (18):

\footnotetext{
${ }^{14}$ As Richard Feldman wrote: "We can say that what I assert by uttering 'I was insulted yesterday' is something that can be true for, or relative to, one person at one time, while being false relative to some other person at the same or some other time. So you and I assert the same thing by uttering 'I was insulted yesterday' and this thing may be true for me when I assert it and false for you when you assert it." (80, p. 79)
} 
(19) Jones said that, too.

To be sure, as it stands, (19) is ambiguous between Jones' having said that Dorsky had been injured and Jones' having said that she herself had been injured. But if Jones has never heard of Dorsky, and if this is common knowledge in the context of (19), the report that Jones said that, too will be taken to mean that Jones said that she herself had been injured; and, given (17), this report intuitively comes out true.

Here is some more evidence from speech reports that suggests that at least in some sense, (17) and (18) say the same thing:

(20) Jones said that she had been injured, and so did Dorsky.

(21) Jones said that she had been injured, and Dorsky said it, too.

(20) is ambiguous between a "sloppy" and a "strict" reading, and so is (21). ${ }^{15}$ Either Dorsky said that she herself had been injured, or she said that Jones had been injured. But the mere availability of the sloppy reading is enough to pose a problem for the standard theories. For, the propositional contents of (17) and (18) are different and cannot play the role of what is said, if this is to be judged and reported as being the same.

The standard response to this sort of cases has been to point out that the sentences used by Jones and Dorsky are the same, and then suggest that when people use the same sentence or utter the same words, it is usually fine to report them as having said the same thing, even though, strictly speaking, they said different things, since they expressed different propositions. In sections 4.4. and 4.5., I will show that this response is unsatisfactory, because it fails to generalize.

\subsection{Same Implications, Same Things Said}

It is because of examples like these that some philosophers started to doubt that the notion of what is said had any determinate and precise sense. Lewis wrote: "Unless we give it some special technical meaning, the locution 'what is said' is very far from univocal. It can mean the propositional content, in Stalnaker's sense (horizontal or diagonal). It can mean the exact words. I suspect that it can mean almost anything in between" $(81$, p. 97$){ }^{16}$

Ziff (72) offers other examples that similarly show how versatile the notion of what is said can be. Here is an example inspired by one of Ziff's. Suppose that Jones and Dorsky went to a certain party, to which Miles could not go. Miles now wants to know how the party went. He asks Jones, and she says:

\footnotetext{
${ }^{15}$ The sloppy/strict distinction has been much discussed in the linguistic literature on ellipsis and anaphora. See eg Lasnik (89), Lappin (97), Buring (03).

${ }^{16}$ Stalnaker's horizontal propositional contents are the usual propositions expressed, eg for (17), that Jones has been injured prior to $t$, where $t$ is the time of her utterance of (17), while the diagonal contents correspond more or less to linguistic meanings.
} 
(22) I should have stayed home and watched television.

Later, Miles asks Dorsky, who says:

(23) It was the lousiest party I've ever been to in my whole life.

Miles might well reply:

(24) Jones said that, too.

Or, talking yet to someone else who did not go to the party, Miles might report:

(25) You didn't miss much. Both Jones and Dorsky said that the party was boring.

Although the intuitions here are not very robust, it is still true that in everyday life, we make reports of this sort. It is not unusual to report two people as having said the same thing when their utterances have some implication in common, and that implication is relevant in the context of the report. Thus, while Jones does not literally say in (22) that the party was boring, what she does say, viz. that she should have stayed at home and watched TV, implies, given some contextual background, that the party was boring. And similarly for (23).

Here is another example in which the fact that one utterance entails another makes it possible to report them as saying the same thing. Suppose that Prof. Jones says to her class:

(26) Everyone should go to Prof. Dorsky's lecture tomorrow night.

The next day, someone tells Sonia, one of Jones' students:

(27) You should go to the lecture tonight.

Sonia might reply:

(28) Yeah, Professor Jones said that, too.

Now, Jones in (26) did not say anything explicitly about Sonia. She said something more general, namely, that everyone should go to the lecture. This entails that Sonia, too, should go to the lecture, and this might be what makes us feel that what is said in (27) has already been said in (26). Note, though, that if you exchange the sentences uttered in (26) and (27), the report in (28) will no longer sound correct.

A variety of similar cases have been noted and discussed by Cappelen and Lepore (97). In this paper, though, I do not want to press upon this kind of cases. I only want to point out certain differences between utterances that we report as saying the same thing because they have some implication in common and the other cases discussed in this paper. In those other cases, there is normally no entailment or implication shared by utterances reported as saying the same thing, such as (17) and (18). True enough, it follows as well from Jones' having been injured as from Dorsky's having been 
injured that someone has been injured. But it is clearly not because of this that we report (17) and (18) as saying the same thing. For, if I say "Jones has been injured" and then you say "Dorsky has been injured," I certainly cannot correctly reply "That's what I've just said." Now, it is also true that both the truth of (17) and the truth of (18) pragmatically entail, as some might say, that some speaker has been injured. Although this is indeed an implication shared by (17) and (18), we are going to see that this sort of implication is probably not enough to explain why we can so easily report what is said as being the same.

Another difference is that in the cases considered in sections 2.1., 4.1., 4.2. and 4.4., not only is it fine to reply That's what so-and-so said, too, but it is generally just as fine to say, That's exactly what so-and-so said, too. On the other hand, if we report that the same thing has been said based on some implication shared by the two utterances, adding 'exactly' makes a huge difference, and what had been seen as a fine report will no longer sound correct.

\subsection{Different Meanings, Different Propositions, Same Things Said}

Let us take stock. We have seen that when different people say "I have been injured," there is the intuition that, at least in a sense, they are saying the same thing, for each is saying that he or she has been injured. The usual way of dealing with such cases is to point out that those people are all using the same sentence, which would then ground the intuition that they are saying the same thing - for, after all, they are uttering the same words.

In this and in the next section, I want to show that this explanation is not quite satisfactory. Although using the same sentence may partly account for the intuition that the same thing has been said, that cannot be the end of the story. Even when the propositions expressed by the two utterances are different, it is neither necessary nor sufficient to use the same sentence in order to be saying the same thing, or for the report that the same thing has been said to come out intuitively true.

Suppose that Wednesday evening, after Dorsky's lecture on contextualism, Jones tells Miles:

(29) I enjoyed this lecture very much.

Next week, Miles sees Sonia, who was also at Dorsky's lecture. Sonia says:

(30) I very much enjoyed Prof. Dorsky's lecture last Wednesday.

Miles might correctly reply to Sonia:

(31) That's what Jones said, too.

The sentences used by Jones and Sonia are different, and their linguistic meanings are different. Had Jones used the sentence that Sonia had used, she could not have been referring to that same lecture, which was the same day as her utterance, and not the 
previous Wednesday. Still, there is an important sense in which Jones and Sonia are saying the same thing, for each is saying that she enjoyed a certain lecture, Dorsky's lecture on contextualism. However, the propositional contents that Kaplanian theories assign to (29) and (30) are different, the first being that Jones enjoyed that lecture, and the second, that Sonia enjoyed it, and there is no entailment from either content to the other.

As another example, consider this dialogue between Jones and Miles:

(32) I am always in disagreement with the Chair of my department.

(33) That's what Dorsky said that, too.

Without further contextual cues, (33) is ambiguous. What is it that Dorsky said? Suppose that Jones is in the Philosophy Department, whose Chair is Prof. Phillips, while Dorsky is in the Linguistic Department, whose Chair is Prof. Lindberg. Then Dorsky might have said any of the following:

(34) Jones is always in disagreement with the Chair of her department.

(35) Jones is always in disagreement with Phillips.

(36) I am always in disagreement with the Chair of the Philosophy Department.

(37) I am always in disagreement with Phillips.

(38) I am always in disagreement with the Chair of my department.

(39) I am always in disagreement with Lindberg.

What (32) has in common with (34) and (35) is the usual propositional content. What (32) has in common with (36) and (37) is what we might call a speaker-neutral content. Note, though, that part of the speaker-related information in (32) has been resolved, so to speak. The person with whom the speaker is said to be always in disagreement has been identified as Phillips, the Chair of the Philosophy Department. The speaker-neutral content that allows Miles to report Dorsky as having said the same thing as Jones is, then, being on very good terms with Phillips.

Finally, what (32) has in common with (38) and (39) is yet another speaker-neutral content: being always in disagreement with the chair of one's own department. To be sure, (32) and (38) have something more in common: they are utterances of the same sentence. That is perhaps why the report in (33) sounds much better when it reports (38) rather than (39).

At any rate, my main point here is that (36) and (37), in which Dorsky says that she in always in disagreement with a certain person, to wit, Phillips, can be heard and reported as saying the same thing as (32), in which Jones says that she herself is always in disagreement with Phillips. However, neither are the propositional contents of these utterances the same, nor are the sentences uttered the same or synonymous.

Our last example may also be used to show that not just "anything in between" [propositional content and the words uttered] can play the role of what is said. For, suppose that Dorsky says: 
(40) Jones is always in disagreement with the Chair of my department.

There is no way of correctly reporting (40) as saying the same thing as (32). If Miles' reply in (33) were based on Dorsky's utterance of (40), it would be considered false. The interesting thing is that (40) and (36) or (37) are, so to speak, symmetrical with respect to (32). If you take the sentence uttered by Jones, viz. I am on very good terms with the Chair of my department, and resolve the definite description 'the Chair of my department,' or just the possessive 'my department', you obtain the sentences uttered in (37) and (36). Similarly, if you take Jones' sentence and resolve only the indexical 'I', you obtain the sentence uttered in (40). However, (36) and (37), on the one hand, and (40) on the other, behave very differently in qualifying as saying the same thing as (32).

\subsection{Again, Same Meanings, Different Things Said}

Just as using the same sentence is not required for the same thing to be said, it is not enough either. Consider the following (minimal) pair of situations:

(i) speaker-neutral what is said

(41) I am a fool. (Jones talking to Miles)

(42) I am a fool. (Olaf talking to Miles)

(43) That's what Jones said, too. (Miles' reply to Olaf)

(ii) addressee-neutral what is said

(44) You are a fool. (Jones talking to Sonia, overheard by Miles)

(45) You are a fool. (Miles talking to Olaf)

(46) *That's what Jones said, too. (again, Miles talking to Olaf)

There is a striking asymmetry between the $1^{\text {st }}$ and the $2^{\text {nd }}$ person pronoun in how they behave in speech reports. Consider (43). As it stands, it is ambiguous between Jones' saying that Olaf is a fool and her saying that she herself is a fool. If it is common knowledge in the context of (43) that Jones has never heard of Olaf and has no idea who he or she is, the dominant reading of (43) will be its sloppy reading, and (43) will be true in virtue of Jones' having uttered (41). However, if we try the same sort of sloppy report by simply replacing 'I' by 'you', no such report will be available. For, people have the strong intuition that (46) is not ambiguous, but downright false (assuming that Jones never said that Olaf was a fool).

The asymmetry between cases (i) and (ii) raises the following problem for the standard theories. There, propositional contents play the role of what is said. But (41) and (42) have different contents, and still, at least in a sense, they say the same thing, and, properly disambiguated, the report in (43) is intuitively true. One might think that this happens because the sentences uttered in (41) and (42) are the same. But 
take (44) and (45). There, too, the sentences uttered are the same, but we do not get a sloppy reading for (46). That report is not ambiguous, but false. What this shows is that something is missing in the account that the standard theories provide for case (i) to begin with.

Note, however, that if the reporter explicitly mentions the person that the reportee was talking to, then the use of the $2^{\text {nd }}$ person pronoun will similarly give rise to the strict/sloppy ambiguity in the report of what has been said. For, consider:

(47) That's what Jones said, too, to Sonia. (Miles talking to Olaf)

(48) That's what Jones told Sonia.

The reports in (47) and (48) are ambiguous between Jones' telling Sonia that Olaf is a fool and her telling Sonia "You are a fool." Again, if it is part of the contextual background that Jones couldn't be talking of Olaf, then the sloppy reading prevails and the reports come out true on the grounds of Jones' utterance of (44). ${ }^{17}$

The difference between the $1^{\text {st }}$ person pronoun and $3^{\text {rd }}$ person and demonstrative pronouns is probably even more striking. Consider:

(i) pronoun-reference-neutral what is said

(49) She is a fool. (Jones, referring to Sonia)

(50) She is a fool. (Olaf, referring to Mrs. Li)

(51) *That's what Jones said, too. (Miles' reply to Olaf)

(ii) demonstrative-reference-neutral what is said

(52) These are healthy. (Jones, talking of carrots)

(53) These are healthy. (Alex, talking of caramel candies)

(54) *That's what Jones said, too. (Miles' reply to Alex)

Intuitively, neither (51) nor (54) are ambiguous. There is only one way to understand these reports, which is that Jones said that Mrs. Li was a fool, and that she said that caramel candies were healthy. Now, if uttering the same sentence is supposed to account for certain cases in which we can correctly report that the same thing has been said, then why is it that in other cases, such as those involving demonstrative pronouns, the prediction turns out to be wrong? Until it can provide an answer to this question, the standard theory of what is said proves to be very limited.

As a final remark, we can have sloppy readings even with the $3^{\text {rd }}$ person and demonstrative pronouns, provided that what the reportee was talking about and referring to is made explicit in the report:

\footnotetext{
${ }^{17}$ In some exceptional cases, it is possible to get the strict/sloppy ambiguity with the $2^{\text {nd }}$ person pronoun even if the person talked to is not explicitly mentioned. Here is one. Miles says to his wife: "You are the loveliest woman ever." She replies: "That's what every husband says in the early years of marriage." But it is likely that in cases such as this, we get the sloppy reading precisely because the strict reading is pragmatically unavailable.
} 
(55) That's what Jones said, too, of Sonia. (Miles' reply to Olaf)

(56) That's what Jones said, too, for carrots. (Miles' reply to Alex)

But the fact remains that there is an interesting asymmetry between the $1^{\text {st }}$ person and the other pronouns, and any good theory of what is said should try to account for it.

\section{$5 \quad$ Linguistic Meaning $=$ What Is Said}

Although most philosophers take the distinction between linguistic meaning and what is said to be essential and well-delineated, the usefulness of this distinction has been questioned in the past. We have already noted Lewis' skeptic attitude. In a somewhat more positive vein, Feldman writes: "We can say that there is only one meaning - the one which Kaplan calls 'character'. When two people utter the same indexical sentence, they assert the character of that sentence. But that character may be true relative to an index containing one person and false relative to an index containing the other" (80, p. 81). ${ }^{18}$ To my knowledge, Feldman himself did not develop this proposal, and it is unclear how he would have dealt with the apparent counterexamples, such as the cases in which intuitively the same thing has been said, even though different sentences have been uttered (sections 2.1, 4.1 and 4.4), or the cases in which the same sentence has been uttered, yet the reports of the same thing having been said come out intuitively false (section 4.5). What I would like to do in this final section is suggest, albeit in very rough lines, how this sort of proposal can be made to work regardless of those problems.

\subsection{What Is Said, What Is Talked About, and Reported Speech}

It will be helpful to begin by laying down the main tenets of our proposal :

a) what is said by a given utterance is nothing more or less than the linguistic meaning of the sentence uttered;

b) the linguistic meaning (of a sentence) is something that can be true with respect to some things while being false with respect to some other things;

c) when we make an assertion, we do not merely assert what the sentence uttered means in virtue of its linguistic meaning, but we assert it of, or about, something;

d) the linguistic meaning of indexicals, proper names, and other directly referential expressions is presuppositional. That is to

\footnotetext{
${ }^{18}$ The notion of an index comes from the Index Theory, as in Lewis (72). An index consists of a number of parameters, such as an agent, a time, a place; roughly, all the shiftable contextual parameters relevant to interpreting a given utterance.
} 
say, the presupposition encoded in the meaning normally scopes out of the negation or other operators, and it is normally common knowledge among the speaker and her audience which things satisfy which presuppositions;

e) when we report what is said by some utterance as being the same (or different) as what is said by some other utterance, we presuppose it known in the context of the report what the reported utterances are respectively about.

Since it is meanings, not propositions, that are presupposed, and since meanings are not true or false tout court, but true or false of things (times, places, objects, situations), instead of asking whether a given presupposition is satisfied in a given context, we must ask whether it is satisfied, in a given context, of a given thing. But apart from this proviso, our proposal is neutral on the question of how to understand or formally account for the notion of presupposition.$^{19}$

To get a better grip on it, it will help to see how this account works on a particular example. Consider Sonia who, holding up a carrot in her hand, says to Alex:

(57) This is healthy.

Since the linguistic meaning of 'this', that is, the condition of being a salient, proximal object, is lexically marked as a presupposition, the question of which objects happen to satisfy this presupposition will supposedly be common knowledge in the context of (57). And since the carrot that Sonia holds up in her hand most obviously meets this condition, she will manage to say something about it, viz. that it is healthy. ${ }^{20}$ Now, the linguistic meaning of the whole sentence is something that will be true with respect to some things at some times and false with respect to the same or different things at the same or some other time. For example, it is true of the carrot that Sonia is holding up in her hand and of the situation in which she is uttering (57), but it is false of the same carrot relative to the situation in which Sonia utters (57) while holding up a caramel candy in her hand (because the carrot is no longer salient, it is no longer "a this"), and it is again false of the candy itself, because caramel candies are not healthy (or so we assume).

The presuppositional behavior of indexicals and names accounts for the fact that when we use a word like 'this', there is normally something that we want to talk about. But it also accounts for the fact that when we report what someone else has said, we cannot just use in our report the same sentence that this person has used. Consider the following report, as uttered in a situation in which the most salient thing, attended to by the speaker and the hearer together, is a certain caramel candy:

(58) Sonia said that this was healthy.

\footnotetext{
${ }^{19}$ For instance, most theories along the lines of Stalnaker's pioneering proposal (cf. Stalnaker (73)) would work fine enough for d) and e). If we were to choose, we would opt for some variant of the so-called binding theory of presupposition (cf. van der Sandt (92), Geurts (99)).

${ }^{20}$ For a discussion of this "procedural" role of linguistic meaning in utterance interpretation, and in particular in reference resolution, see my (05).
} 
There is no way in which Sonia's utterance of (57) could make the report in (58) come out true. The reason why this is so is that the presupposition carried by 'this' cannot be "accommodated locally," to use the jargon. The description encoded in the linguistic meaning of the demonstrative in (58) will scope out of the indirect discourse operator 'said that', which means that it will be used to single out something in the context of the report, rather than in the context in which the reported utterance was made. That is why (59), but not (60), may serve as an approximative paraphrase of (58):

(59) There is a salient, proximal object such that Sonia said that it was healthy.

(60) *Sonia said that there was a salient, proximal object and that it was healthy.

Finally, let me try to make it more clear what tenet e) amounts to. Reconsider Sonia's utterance, made in reference to the carrot, followed by a reply from Alex:

(61) This is healthy.

(62) Jones said that, too.

When Alex reports that Jones said what Sonia has just said, the issue of what it was that Jones was talking about will be presupposed in the context of the report. Given that Alex does not explicitly mention anything as being what Jones was talking about when she said the same thing as Sonia, it will be understood that Jones was talking of the same thing that Sonia is talking about, namely the carrot. ${ }^{21}$ This is why the report will come out intuitively false when Alex makes it on the grounds of Jones' having uttered the same sentence as Sonia did, while referring to something that was not a carrot, say, to some candy. However, as it is known from the literature (Geurts (99)), presuppositions can sometimes be anchored to an explicit element in the discourse. That also happens in the case of reported speech, where the presupposition of what the reported utterance was about may be bound to something explicitly mentioned, in the same way in which anaphoric expressions get bound to elements in their discourse environment:

(63) This is healthy. - Jones said that, too, of a candy.

\subsection{Conclusion: an Agenda for the Future}

I started this paper with a presentation of what we might call the received wisdom on what is said, one of whose central tenets is the distinction between linguistic meaning and what is said. We then saw two main types of cases that prima facie motivate this distinction, the "different meanings, same thing said" cases and the "same meanings,

${ }^{21}$ Obviously, Jones need not have been talking about the vary same carrot that Sonia has been holding up in her hand. Jones might have pointed to a different carrot, or she could have said "Carrots are healthy." Since the example involves some subtle issues about reference to kinds and deferred reference, I will not press it any further. 
different things said" cases, as I called them. We also saw that even some radically opposed views, like contextualism and minimalism, appear to agree on the question of what it is that directly referential expressions such as proper names and personal and demonstrative pronouns contribute to what is said. Then we moved to a series of cases that square very badly with the distinction linguistic meaning vs. what is said. In particular, we often get the intuition that the same thing has been said, even though the reported utterances do not express the same (traditional) proposition, nor do the sentences uttered have the same linguistic meaning. We have also seen cases in which utterances of the same sentence are reported as saying the same thing, even though, again, different propositions are expressed. However, such cases do not generalize that easily, and we have noted interesting asymmetries among the ways in which $1^{\text {st }}$ person, $2^{\text {nd }}$ person and other pronouns affect speech reports. In the end, we outlined, in a very programmatic way, a positive account that takes what is said to be nothing more or less than the linguistic meaning of the sentence uttered. The three elements deployed in the construal of our account are linguistic meanings, what is talked about, and the semantics of reported speech. Elaborating this account in due detail remains a project for the future.

\section{References}

Bach, K.: Conversational Impliciture. Mind and Language 9 (1994)

Bach, K.: The Semantics/Pragmatics Distinction: What It Is and Why It Matters, in Turner, K. (ed.) The Semantics/Pragmatics Distinction from Different Points of View. Elsevier (1999)

Bach, K.: Seemingly Semantic Intuitions, in Campbell, J. et al. (eds.), Meaning and Truth. Seven Bridges Press (2002)

Borg, E.: Minimal Semantics. Oxford: Clarendon Press (2004)

Buring, D.: Binding Theory. Cambridge University Press (2003)

Cappelen, H. and E. Lepore: On an Alleged Connection Between Indirect Speech and the Theory of Meaning. Mind and Language 12 (1997)

Cappelen, H. and E. Lepore: Insensitive Semantics. Oxford: Blackwell (2005)

Carston, R.: Thoughts and Utterances: The Pragmatics of Explicit Communication. Oxford: Blackwell (2002)
Crimmins, M. and J. Perry: The Prince and the Phone Booth: Reporting Puzzling Beliefs. The Journal of Philosophy 86 (1989)

Feldman, R.: Saying Different Things. Philosophical Studies 38 (1980)

Frege, G.: Logic (1897) in Beaney, K. (ed.), The Frege Reader. Oxford: Blackwell (1997)

Geurts, B.: Good News for the Description Theory of Names. Journal of Semantics 14 (1997)

Geurts, B.: Pronouns and Presuppositions. Elsevier (1999)

Grice, P.: Studies in the Ways of Words. Cambridge MA: Harvard University Press (1989)

Heim, I. and A. Kratzer: Semantics in Generative Grammar. Oxford: Blackwell (1998)

Evans, G.: Does Tense Logic Rest Upon a Mistake? in Vermazen, B. and M. B. Hintikka, Essays on Davidson: Truth and Interpretation. Oxford University Press (1979)

Kamp, H. and U. Reyle: From Discourse to Logic. Kluwer Dordrecht (1993) 
Kaplan, D.: On Demonstratives (1977) in Almog, J. et al. (eds.), Themes from Kaplan. Oxford University Press (1989)

King, J. and J. Stanley: Semantics, Pragmatics, Recanati, F.: Literal Meaning. Oxford and the Role of Semantic Content (2002)

Lappin, S.: The Interpretation of Ellipsis, in Lappin S. (ed.) The Handbook of Contemporary Semantic Theory. Oxford: Blackwell (1996)

Lasnik, H.: Essays on Anaphora. Kluwer Dordrecht (1989)

Levinson, S.: Presumptive Meanings: The Theory of Generalized Conversational Implicatures. Cambridge MA: MIT Press (2000)

Lewis, D.: General Semantics, in Davidson, and G. Harman (eds.), Natural Language Semantics. Reidel Dordrecht (1972)

Lewis, D.: Index, Context and Content, in Kanger, S. and S. Ohman (eds.), Philosophy and Grammar. Reidel Dordrecht (1980)

Partee, B.: Some Structural Analogies between Tenses and Pronouns in English. The Journal of Philosophy 70 (1973)

Partee, B.: Binding Implicit Variables in Quantified Contexts. Papers of Chicago Linguistic Society (1989)

Perry, J.: Reflexivity, Indexicality and Names in Kunne, W., et al. (eds.), Direct Reference, Indexicality, and Propositional Attitudes. The CSLI Publications (1997)

Perry, J.: Reference and Reflexivity. The CSLI Publications (2001)

Predelli, S.: Contexts. Meaning, Truth, and the Use of Language. Oxford University Press (2005)

Predelli, S.: Painted Leaves, Context and Semantic Analysis. Linguistics and Philosoph (forthcoming)

Prior, A.: Time and Modality. Oxford University Press (1957)

Recanati, F.: Direct Reference: from Languag to Thought. Blackwell Oxford (1993)

Recanati, F.: What Is Said. Synthese 128 (2001)
Recanati, F.: Oratio Obliqua, Oratio Recta: An Essay on Metarepresentations. The MIT Press (2003) University Press (2004) van der Sandt, R.: Presupposition as Anaphora Resolution. Journal of Semantics 9, (1992) Salmon, N.: Frege's Puzzle. The MIT Press (1986)

Saul, J.: Speaker Meaning, What Is Said, and What Is Implicated. Nous 36 (2002)

Soames, S.: Beyond Rigidity: the Unfinished Semantic Agenda of 'Naming and Necessity'. Oxford University Press (2002)

Stalnaker, R.: Presuppositions. Journal of

. Philosophical Logic 2 (1973)

Stalnaker, R.: Assertion, in Cole, P. (ed.), Syntax and Semantics 9, Academic Press, London (1978)

Stalnaker, R.: Context and Content. Oxford University Press (1999)

Stanley, J.: Context and Logical Form. Linguistics and Philosophy 23 (2000)

Stanley, J.: Semantics in Context, in Preyer, G. (ed.), Contextualism. Oxford University Press (2005)

Stojanovic, I.: What to Say on What Is Said, in Blackburn P. et al. (eds.), Modeling and Using Context. Springer-Verlag, LNAI 2680, Berlin (2003)

Stojanovic, I.: A Different Story about Indexicals. ILLC Research Report PP-200505, Amsterdam (2005)

Taylor, K.: Truth and Meaning. Oxford: Blackwell (1998)

Taylor, K.: Misplaced Modification and the Illusion of Opacity, in O'Rourke et al (eds.)., Situating Semantics: Essays on the Philosophy of John Perry. The MIT Press, Cambridge (forthcoming)

Ziff, P.: What Is Said, in Davidson, D. and G. Harman (eds.), Natural Language Semantics. Reidel Dordrecht (1972) 